\title{
Compostos fenólicos, carotenóides e atividade antioxidante em produtos vegetais
}

\section{Phenolic compounds, carotenoids and antioxidant activity in plant products}

\author{
Marília Lordêlo Cardoso Silva ${ }^{1}$; Renata Silva Costa ${ }^{2}$; \\ Andréa dos Santos Santana ${ }^{3}$; Maria Gabriela Bello Koblitz ${ }^{4 *}$
}

\begin{abstract}
Resumo
O processo respiratório e diversas reações oxidativas das células aeróbicas levam à formação de radicais livres, que contribuem para o aparecimento de diversas doenças. As células humanas dependem de sua capacidade antioxidante para fornecer proteção contra os efeitos prejudiciais de radicais livres e espécies reativas do oxigênio, que são conseqüências inevitáveis da vida aeróbica. Vários estudos epidemiológicos indicam que a alta ingestão de produtos vegetais está associada com uma redução no risco de uma variedade de doenças crônicas como aterosclerose e câncer, efeitos que têm sido particularmente atribuídos aos compostos que possuem atividade antioxidante nos vegetais: vitaminas C e E, os compostos fenólicos, especialmente os flavonóides, e os carotenóides. Compostos fenólicos agem como antioxidantes, não somente por sua habilidade em doar hidrogênio ou elétrons, mas também em virtude de seus radicais intermediários estáveis, que impedem a oxidação de vários ingredientes do alimento, particularmente de lipídios. Carotenóides são constituídos de cadeias de polienos, em um longo sistema de duplas ligações conjugadas, rico em elétrons, responsável pela atividade antioxidante desses compostos: tanto na absorção do oxigênio singlet quanto de radicais livres, para interromper as reações em cadeia onde eles estão envolvidos. Este trabalho teve por finalidade revisar as diferentes formas de avaliação qualitativa e quantitativa dos principais componentes não-nutrientes antioxidantes em alimentos de origem vegetal: compostos fenólicos e carotenóides.
\end{abstract}

Palavras-chave: Avaliação qualitativa, avaliação quantitativa, componentes não-nutrientes

\begin{abstract}
The respiratory process and several aerobic cells oxidative reactions lead to the formation of free radicals which contribute to the appearance of different diseases. The human cells depend on their antioxidant ability to provide protection against the prejudicial effects of free radical and reactive oxygen species that are inevitable consequences of aerobic life. Several epidemiologic studies indicate that high plant products ingestion is associated to a reduction in the hazard of a variety of cronical diseases such as arteriosclerosis and cancer. These effects have been specifically attributed to the plant compounds that have antioxidant activity: vitamin $\mathrm{C}$ and $\mathrm{E}$, phenolic compounds, specially flavonoids, and carotenoids.
\end{abstract}

1 Universidade Estadual de Feira de Santana. Departamento de Tecnologia. Engenharia de Alimentos. E-mail: lilaengal@yahoo. com.br

2 Universidade Estadual de Feira de Santana. Departamento de Tecnologia. Engenharia de Alimentos. E-mail: rsc212000@gmail. com

3 Universidade Estadual de Feira de Santana. Departamento de Ciências Biológicas. Programa de Pós-graduação em Recursos Genéticos Vegetais. E-mail: santana.andrea@gmail.com

4 Universidade Estadual de Feira de Santana. Departamento de Tecnologia. Engenharia de Alimentos. E-mail: mkoblitz@gmal. com

* Autor para correspondência 
Phenolic compounds act as antioxidants, not only for their ability to donate hydrogen atoms or electrons, but also because of their stable intermediary radicals, that prevent the oxidation of many food ingredients, especially lipids. Carotenoids are built by polyene chains in a long conjugated double bonds system, electron rich, which is responsible for the antioxidant activity of these compounds, by the absorption of singlet oxygen and free radicals, to interrupt the chain reaction they are involved in. This paper had as a goal to review the different qualitative and quantitative evaluation methods of the main non-nutrient antioxidants in plant originated foods: phenolic compounds and carotenoids.

Key words: Qualitative evaluation, quantitative evaluation, non-nutrient components

\section{Introdução}

O processo respiratório e diversas reações oxidativas, que ocorrem nas células aeróbicas, levam à formação de radicais livres, que causam danos ao organismo e contribuem para o aparecimento de muitas doenças, tais como: inflamações, tumores malignos, mal de Alzheimer e doenças cardiovasculares, bem como aceleram o processo de envelhecimento (SIKORA et al., 2008). Por isso, as células humanas dependem de certa capacidade antioxidante para fornecer proteção contra os efeitos prejudiciais de radicais livres e espécies reativas do oxigênio, que são conseqüências inevitáveis da vida aeróbica. Para alcançar uma proteção eficiente, os tecidos dispõem de um sistema antioxidante integrado, que consiste de um arranjo de diversos componentes lipossolúveis (vitamina E; carotenóides), hidrossolúveis (ácido ascórbico; glutatinona) e enzimáticos (glutatinona peroxidase; superóxido dismutase; catalase) (McLEAN et al., 2005).

Nos últimos anos, uma atenção crescente tem sido dedicada ao papel da dieta na saúde humana. Vários estudos epidemiológicos indicaram que a alta ingestão de produtos vegetais está associada com uma redução no risco de uma variedade de doenças crônicas como aterosclerose e câncer. Estes efeitos têm sido particularmente atribuídos aos compostos que possuem atividade antioxidante. Os principais antioxidantes nos vegetais são as vitaminas $\mathrm{C}$ e $\mathrm{E}$, os carotenóides e os compostos fenólicos, especialmente os flavonóides. Esses antioxidantes absorvem radicais livres e inibem a cadeia de iniciação ou interrompem a cadeia de propagação das reações oxidativas promovidas pelos radicais (PODSEDEK, 2007). Além da ingestão de frutas e vegetais, que são recomendados como fontes de compostos antioxidantes, acredita-se que a suplementação da dieta com ervas, contendo altas concentrações de compostos capazes de desativar radicais livres, tenha também efeitos benéficos (CAPECKA; MARECZEK; LEJA, 2004).

As espécies reativas do oxigênio (ERO) e seu provável envolvimento em algumas fisiopatologias humanas vêm atraindo o interesse de diversos setores da sociedade envolvidos com a saúde pública (LAGUERRE; LECOMTE; VILLENEUVE, 2007). O estresse oxidativo, causado pelo desbalanço entre os sistemas antioxidantes e a produção de compostos oxidativos (radicais livres, ERO) aparentemente está associado com diversas doenças de cunho multifatorial, especialmente os vários tipos de câncer, doenças cardiovasculares e desordens inflamatórias. Os mecanismos pelos quais essas patologias se desenvolvem, geralmente envolvem alterações oxidativas de moléculas consideradas críticas, o que inclui proteínas, carboidratos, ácidos nucléicos além das substâncias envolvidas na modulação da expressão gênica e em respostas inflamatórias (KAWANISHI et al., 2002; LAGUERRE; LECOMTE; VILLENEUVE, 2007).

O organismo humano desenvolveu sistemas de defesa para lidar com o estresse oxidativo. Essa defesa inclui sistemas enzimáticos (superóxido dismutase, catalases, glutationa peroxidase e sistemas tioredox) que são reconhecidamente muito eficientes na detoxificação de ERO. Os principais antioxidantes não-enzimáticos presentes no organismo humano são a glutationa, a bilirubina, os hormônios sexuais estrogênicos, o ácido úrico, a 
coenzima Q, a melanina, a melatonina, o $\square$-tocoferol e o ácido lipóico (McLEAN et al., 2005). Além disso, diversos estudos já comprovaram que antioxidantes exógenos, obtidos dos alimentos, são essenciais para a resistência ao estresse oxidativo. Esses antioxidantes são obtidos sobretudo de produtos de origem vegetal: compostos fenólicos, ácido ascórbico e carotenóides (LAGUERRE; LECOMTE; VILLENEUVE, 2007). Estudos epidemiológicos mostraram haver uma estreita correlação entre o consumo de frutas e uma redução no risco de doenças crônicas. Atualmente acreditase que a combinação de vitaminas, minerais, compostos fenólicos antioxidantes e fibra seja responsável pelo efeito desejado. Paralelamente à esse reconhecimento vem crescendo o consumo de frutas tropicais, consideradas exóticas, em todo o mundo (VASCO; RUALES; KAMAL-ELDIN, 2008).

Um antioxidante é qualquer substância capaz de retardar ou impedir danos devidos à oxidação (como rancificação e formação de off-flavors em alimentos) estando presente em pequenas concentrações, quando em comparação com o agente oxidante. As substâncias antioxidantes podem apresentar diferentes propriedades protetivas e agir em diversas etapas do processo oxidativo, funcionando por diferentes mecanismos e são, portanto, classificadas em duas categorias principais: antioxidantes primários e secundários. São considerados primários os compostos de ação antioxidante capazes de inibir ou retardar a oxidação por inativação de radicais livres graças à doação de átomos de hidrogênio ou de elétrons, o que transforma os radicais em substâncias estáveis. Os antioxidantes secundários apresentam uma grande variedade de modos de ação: ligação de íons metálicos (alteração de valência); inativação de ERO, conversão de hidroperóxidos em espécies não-radicalares ou absorção de radiação UV (MAISUTHISAKUL; SUTTAJT; PONGSAWATMANIT, 2007).

A busca por antioxidantes naturais para produtos alimentícios, cosméticos e farmacêuticos vem representando um importante desafio para a pesquisa industrial nos últimos 20 anos (LAGUERRE; LECOMTE; VILLENEUVE, 2007). Nesses produtos, há um grande interesse pelo estudo da oxidação lipídica, em virtude da deterioração que este tipo de dano oxidativo pode causar (rancificação, perda de aromas e formação de off-flavors, rejeição do consumidor). A oxidação lipídica é um processo complexo que envolve uma variedade de radicais livres e é influenciada pela temperatura, pela luz, presença de $\mathrm{O}_{2}$, além das propriedades físico-químicas do produto e da presença de possíveis iniciadores e catalisadores da reação. O uso de antioxidantes em produtos contendo lipídios é uma das principais formas de se minimizar a rancificação, retardar a formação de produtos tóxicos, manter a qualidade sensorial e nutricional e aumentar a vida-de-prateleira de produtos alimentícios (MAISUTHISAKUL; SUTTAJIT; PONGSAWATMANIT, 2007). Uma vez que os consumidores vêm apresentando rejeição pelo uso de antioxidantes sintéticos, há um crescente interesse na obtenção de substâncias antioxidantes provenientes de produtos vegetais. Além disso, alguns produtos naturais (como extrato de gengibre e de outros temperos) apresentaram, in vitro, maior atividade antioxidante que os produtos sintéticos (MURCIA et al., 2004; PAREJO et al., 2002). Extratos de ervas aromáticas, chá, uva e citros estão entre as principais fontes de antioxidantes naturais estudadas. Apesar da grande quantidade de trabalhos desenvolvidos, muito do potencial existente permanece inexplorado (LAGUERRE; LECOMTE; VILLENEUVE, 2007).

Os vegetais possuem dois tipos de metabólitos: primários e secundários. Enquanto os metabólitos primários respondem pela sobrevivência do vegetal, exercendo função ativa nos processos de fotossíntese, respiração e assimilação de nutrientes; os metabólitos secundários estão intimamente associados à estratégias de defesa das plantas (NASS, 2007). Além disso, por apresentarem atividade biológica contra herbívoros e microrganismos, 
por ex., muitos desses metabólitos são utilizados como inseticidas, fungicidas, etc. (TAYS; ZEIGER, 2004). Os principais metabólitos secundários são distribuídos em três grupos de acordo com sua rota biossintética: terpenos, compostos fenólicos e compostos contendo nitrogênio (TAYZ; ZEIGER, 2004).

Este trabalho teve por finalidade revisar as diferentes formas de avaliação qualitativa e quantitativa dos principais componentes nãonutrientes antioxidantes em alimentos de origem vegetal: compostos fenólicos e carotenóides.

\section{Compostos Fenólicos}

Os compostos fenólicos são substâncias amplamente distribuídas na Natureza, mais de 8000 compostos fenólicos já foram detectados em plantas. Esse grande e complexo grupo faz parte dos constituintes de uma variedade de vegetais, frutas e produtos industrializados. Podem ser pigmentos, que dão a aparência colorida aos alimentos, ou produtos do metabolismo secundário, normalmente derivado de reações de defesa das plantas contra agressões do ambiente. Esses compostos agem como antioxidantes, não somente pela sua habilidade em doar hidrogênio ou elétrons, mas também em virtude de seus radicais intermediários estáveis, que impedem a oxidação de vários ingredientes do alimento, particularmente de lipídios (BRANDWILLIAMS; CUVELIER; BERSET, 1995).
Principais compostos fenólicos encontrados em vegetais

Os compostos fenólicos apresentam, em sua estrutura, vários grupos benzênicos característicos, tendo como substituintes grupamentos hidroxilas (HERNÁNDEZ; PRIETO GONZÁLES,1999). Esta classe de compostos apresenta uma grande diversidade e divide-se em flavonóides (polifenóis) e não-flavonóides (fenóis simples ou ácidos). Os átomos de hidrogênio dos grupos hidroxila adjacentes (orto-difenóis), localizados em várias posições dos anéis $\mathrm{A}, \mathrm{B}$ e $\mathrm{C}$, as duplas ligações dos anéis benzênicos e a dupla ligação da função oxo $(-\mathrm{C}=\mathrm{O})$ de algumas moléculas de flavonóides garantem a esses compostos sua alta atividade antioxidante (HRAZDINA; BORZEL; ROBINSON, 1970; RICE-EVANS; MILLER; PAGANGA, 1996).

Os flavonóides compreendem um grupo de compostos fenólicos amplamente distribuídos nas frutas e nos vegetais, apresentando-se sob muitas variações como flavonóis, flavonas, flavanonas, catequinas (Figura 1A), antocianinas (Figura 1B), isoflavonas e chalconas. Suas principais fontes são: café, cebola, maçã, uva cerveja, vinho tinto e especialmente chá, que contém sobretudo catequinas em sua composição (GRAHAM, 1992; VAN ACQUIRE, 1996).

Na classe dos não-flavonóides estão os derivados dosácidoshidroxicinâmicoehidroxibenzóico(Figura 2). Sua atividade antioxidante está relacionada com a posição dos grupos hidroxilas e também com a proximidade do grupo $-\mathrm{CO}_{2} \mathrm{H}$ em relação ao grupo fenil. Quanto mais próximo esse grupo estiver do grupo fenil, maior será a capacidade antioxidante do grupo hidroxila na posição meta (HRAZDINA; BORZEL; ROBINSON, 1970). 
<smiles>Oc1cc(O)c2c(c1)OC(c1ccc(O)c(O)c1)C(O)C2</smiles>

A<smiles></smiles>

B

Figura 1. Exemplos de flavonóides mais comumente encontrados. A: catequinas e B: antocianinas.<smiles>O=C(O)c1ccccc1</smiles>

A<smiles>CC(=O)c1ccccc1</smiles>

B

Figura 2. Moléculas dos ácidos hidrocinâmico (A) e do hidroxibenzóico (B).

Os principais compostos fenólicos nãoflavonóides derivados dos ácidos hidroxicinâmicos são os ésteres dos ácidos caféico, cumárico e felúrico, que estão presentes em alimentos como maçã, pêra, cereja e damasco. Quanto aos derivados dos ácidos hidroxibenzóicos, podem-se destacar os ácidos salicílico, gálico, elágico, protocatéico e vanílico, que são encontrados em morango, uva, laranja, limão e tangerina (BELITZ; GROSCH, 2004).

Estudos realizados com os compostos fenólicos demonstram sua capacidade antioxidante, assim como seu possível efeito na prevenção de diversas enfermidades cardiovasculares, cancerígenas e neurológicas (HARBORNE; WILLIAMS, 2000; SÁNCHEZ-MORENO, 2002). De maneira geral, a ação benéfica dos compostos fenólicos na saúde humana vem sendo relacionada com a sua atividade antiinflamatória e com a atividade que impede, não só a aglomeração das plaquetas sanguíneas, mas também a ação de radicais livres no organismo. Uma vez que protegem moléculas como o DNA, podem vir a abortar alguns processos carcinogênicos.

\section{Metodologias para determinação de compostos fenólicos}

Métodos de extração

Diversos trabalhos dedicados ao estudo da presença de compostos fenólicos em produtos vegetais podem ser encontrados na literatura recente. A (Tabela 1) reúne alguns desses trabalhos, dando especial atenção à metodologia aplicada para a extração dos compostos anterior à sua quantificação/ identificação. 
Tabela 1. Técnicas de extração de compostos fenólicos.

\begin{tabular}{|c|c|c|c|c|}
\hline Solução extratora & $\begin{array}{l}\text { Tempo de } \\
\text { extração }\end{array}$ & $\begin{array}{l}\text { Temperatura de } \\
\text { extração }\end{array}$ & Outras informações & Referência \\
\hline Etanol & - & - & $\begin{array}{l}\text { Soxleht seguido por } \\
\text { purificação em coluna } \\
\text { cromatográfica de sílica e } \\
\text { carvão ativado }(1: 0,5)\end{array}$ & $\begin{array}{l}\text { FURLONG et al., } \\
2003\end{array}$ \\
\hline Etanol & $06 \mathrm{~h}$ & - & $\begin{array}{l}\text { Soxleht, purificação por } \\
\text { partição com éter de } \\
\text { petróleo e acetona seguida } \\
\text { por precipitação com } \\
\text { acetato de chumbo. }\end{array}$ & $\begin{array}{l}\text { FURLONG et al., } \\
2003\end{array}$ \\
\hline Metanol & - & Ambiente & $\begin{array}{c}\text { Agitação magnética, } \\
\text { partição com hexano e } \\
\text { clarificação com hidróxido } \\
\text { de bário e sulfato de zinco }\end{array}$ & $\begin{array}{l}\text { FURLONG et al., } \\
2003\end{array}$ \\
\hline $\begin{array}{c}\text { Acetona e água } \\
\text { deionizada } \\
(0 \%, 25 \%, 50 \%, \\
75 \% \text { e } 100 \%)\end{array}$ & overnight & $4-10^{\circ} \mathrm{C}$ & - & $\begin{array}{l}\text { YILMAZ; TOLEDO, } \\
2006\end{array}$ \\
\hline Acetona $70 \%$ & $20 \mathrm{~min}$ & $4^{\circ} \mathrm{C}$ & Centrifugação 4200xg & EFRAIM et al., 2006 \\
\hline Éter etílico & $1 \mathrm{~h}$ & Ambiente & $\begin{array}{l}\text { Agitação magnética e } \\
\text { filtração a vácuo }\end{array}$ & $\begin{array}{l}\text { BROINIZI et al., } \\
2007\end{array}$ \\
\hline Metanol 100\% & $12 \mathrm{~h}$ & Ambiente & Agitação magnética & AO et al., 2007 \\
\hline $\begin{array}{c}96 \% \text { n-hexano, } \\
\text { acetona, acetato } \\
\text { de etila, etanol e } \\
\text { metanol }\end{array}$ & $15 \mathrm{~h}$ & - & Soxhlet & $\begin{array}{l}\text { VÁZQUEZ et al., } \\
2008\end{array}$ \\
\hline $\begin{array}{c}\text { Etanol-água }(80 / 20) \\
\text { e metanol-água } \\
(50 / 50)\end{array}$ & $2 \mathrm{~h}$ & - & $\begin{array}{l}\text { Agitador orbital, } \\
\text { recuperação do extrato } \\
\text { por filtração a vácuo e } \\
\text { evaporação do solvente em } \\
\text { rotaevaporador }\end{array}$ & $\begin{array}{l}\text { VÁZQUEZ et al., } \\
2008\end{array}$ \\
\hline $\begin{array}{c}\text { Água e solução } \\
\text { aquosa } \mathrm{Na}_{2} \mathrm{SO}_{3} \text { a } \\
2,5 \%\end{array}$ & $1 \mathrm{~h}$ & $90^{\circ} \mathrm{C}$ & $\begin{array}{l}\text { Reator de vidro com } \\
\text { agitação mecânica }\end{array}$ & $\begin{array}{l}\text { VÁZQUEZ et al., } \\
2008\end{array}$ \\
\hline
\end{tabular}

\section{Quantificação de compostos fenólicos totais}

De um modo geral, o conteúdo de fenóis totais pode ser determinado pelos métodos espectrofotométricos de Folin-Ciocalteu (ROSSI JUNIOR; SINGLETON 1965) ou do azul da Prússia modificado (GRAHAM, 1992), que se baseiam nas reações de oxi-redução entre os compostos fenólicos e íons metálicos.
O método que usa o reagente de Folin-Ciocalteu utiliza a redução pelos fenóis, em meio alcalino, do fosfomolibdato-fosfotungstato, a molibdênio, cuja coloração é azul. O método chamado de azul da Prússia é recomendado para análise de fenóis em uma grande variedade de substratos, pois é menos susceptível à interferência de proteínas que o método de Folin-Ciocalteu. A base química 
daquela metodologia é a redução, pelos grupos hidroxi-fenólicos, de íons $\mathrm{Fe}^{+3}$ a $\mathrm{Fe}^{+2}$, que formam complexos com ferrocianeto, produzindo pigmentos de coloração azul.

Em ambos os casos é necessária a utilização de curva padrão, sendo o padrão mais utilizado o ácido gálico. Por este motivo os resultados são, em geral, expressos em mg de ácido gálico em $100 \mathrm{~g}$ de peso seco da amostra.

\section{Identificação de compostos fenólicos}

Em alguns trabalhos os pesquisadores procuraram identificar os diversos compostos fenólicos presentes nas amostras. A metodologia empregada em alguns artigos está sumarizada na (Tabela 2).

Tabela 2. Técnicas de identificação de compostos fenólicos.

\begin{tabular}{|c|c|c|c|c|}
\hline Técnica & Detector & Coluna & $\begin{array}{c}\text { Eluente/Gás de } \\
\text { arraste }\end{array}$ & Referência \\
\hline Cromatografia gasosa & $\begin{array}{l}\text { Espectro de } \\
\text { massa }\end{array}$ & $\begin{array}{l}\text { Tipo DB- } \\
\text { 5MS (30m x } \\
0,25 \mathrm{~mm})\end{array}$ & Hélio & AO et al., 2007 \\
\hline $\begin{array}{c}\text { Cromatografia líquida de } \\
\text { alta eficiência }\end{array}$ & - & $\begin{array}{c}\text { Tipo } 80 \mathrm{~A} \\
(150 \mathrm{~mm} \times 60 \\
\mathrm{mm})\end{array}$ & $\begin{array}{c}\text { Solvent A } \\
\text { (água:ácidoacético) } \\
\text { e B } \\
\text { (metanol:acetonitrila). }\end{array}$ & AO et al., 2007 \\
\hline $\begin{array}{l}\text { Cromatografia de } \\
\text { permeação em gel }\end{array}$ & $\begin{array}{l}\text { Arranjo } \\
\text { diodo }\end{array}$ & $\begin{array}{l}\text { Tipo HP-PL gel } \\
5 \mu \mathrm{m} \text {, protegida } \\
\text { por coluna de } \\
\text { guarda }\end{array}$ & - & VÁZQUEZ et al., 2008 \\
\hline Espectroscopia FTIR & - & & - & VÁZQUEZ et al., 2008 \\
\hline
\end{tabular}

\section{Carotenóides}

Carotenóides são pigmentos lipossolúveis, amarelos, laranjas e vermelhos, presentes em muitas frutas e vegetais. Em plantas superiores, estão localizados em organelas subcelulares (cloroplastos e cromoplastos). Nos cloroplastos encontramse associados principalmente à proteínas e são, normalmente, mascarados pela presença de outros pigmentos clorofílicos dominantes. Atuam como pigmentos fotoprotetores na fotossíntese e como estabilizadores de membranas. Nos cromoplastos, eles são depositados na forma cristalina (ex. tomates e cenouras) ou como gotículas de óleo (ex. manga e páprica) (KURZ, CARLE; SCHIEBER, 2008).

Os tecidos de plantas comestíveis contêm uma ampla variedade de carotenóides. Os exemplos mais comuns são: tomates (licopeno), cenouras ( $\alpha$ e $\beta$-caroteno), milho (luteína e zeaxantina), pimentas vermelhas (capsantina), urucum (bixina) e batata doce ( $\beta$-caroteno). Outras fontes vegetais de carotenóides são: abóbora, pimentão vermelho e amarelo, inhame, cará, azeitona roxa, repolho roxo, folhas verde-escuras (como brócolis e espinafre), alface, aipo, maçã, damasco, manga, ameixa, frutas vermelhas, melancia, laranja, tangerina, nectarina e mamão. Alguns dos carotenóides apresentam a estrutura cíclica $\beta$-ionona em suas moléculas sendo, portanto, precursores de vitamina A (ex. $\alpha, \beta$ e $\gamma$-caroteno e $\beta$-criptoxantina). Estudos apontam que a função antioxidante dos carotenóides desempenha um papel importante na redução do risco de 
câncer, catarata, ateriosclerose e no processo de envelhecimento (DAMODARAN, PARKIN; FENNEMA, 2008).

Os carotenóides são biosintetizados principalmente por algas no oceano, mas também por plantas e muitos microorganismos e os animais devem obtê-los desses alimentos. O conteúdo de carotenóides nas frutas e vegetais depende de vários fatores como: variedade genética, estádio de maturação, armazenamento póscolheita, processamento e preparo (CAPECKA, MARECZEK; LEJA, 2005).

Do ponto de vista químico, carotenóides são compostos polisoprenóides e podem ser divididos em dois grandes grupos: (a) carotenos ou carotenóides hidrocarbonos: compostos apenas de carbono e hidrogênio (ex. $\alpha$ e $\beta$-caroteno e licopeno) e (b) xantofilas: que são derivados oxigenados dos carotenos e contém pelo menos uma função hidroxi, ceto, epóxi, metoxi ou ácido carboxílico (ex. luteína, zeaxantina e astaxantina) (QUIRÓs; COSTA, 2006).

Acaracterísticaestruturalcomumdoscarotenóides é a cadeia polieno, um longo sistema de ligação dupla conjugada, que forma a "espinha dorsal" da molécula e influencia suas propriedades químicas, físicas e bioquímicas. Esta cadeia pode apresentar grupos terminais cíclicos, que apresentam substituintes contendo oxigênio. O sistema conjugado e rico em elétrons do polieno é responsável pela atividade antioxidante dos carotenóides: tanto na absorção do oxigênio singlet quanto de radicais livres, para interromper as reações em cadeia onde eles estão envolvidos (McNULTY, et al., 2007; QUIRÓS; COSTA, 2006; SIKORA et al., 2008). A presença dessas ligações também facilita a oxidação dos carotenóides, o que provoca uma perda da coloração nos alimentos. É por serem facilmente oxidados, que apresentam atividade antioxidante. Além da proteção celular e in vitro contra oxigênio singlet, os carotenóides inibem a peroxidação de lipídeos em baixas pressões de oxigênio. A eficiência como antioxidante varia entre os diferentes carotenóides, sendo o licopeno considerado o mais eficiente como capturador de oxigênio singlet (DAMODARAN, PARKIN; FENNEMA, 2008).

Principais carotenóides encontrados em produtos vegetais

O $\beta$-caroteno (Figura 3) é o carotenóide que possui maior atividade de provitamina A e é encontrado em diversos vegetais como cenoura, abóbora, manga e mamão (DAMODARAN; PARKIN; FENNEMA, 2008). Street et al. (1994) relataram uma significativa associação entre baixas concentrações de $\beta$-caroteno no plasma e aumento da incidência de infarto do miocárdio. Uma dieta rica em $\beta$-caroteno já foi associada ao menor risco de morte prematura devido às doenças coronarianas (BELLIZI et al., 1994).

Luteína e zeaxantina (Figura 3) são xantofilas resultantes do processo dehidroxilação de $\alpha$-caroteno e $\beta$-caroteno, respectivamente, que possuem atividade de provitamina A. Durante a maturação dos frutos, a conversão a luteína e zeaxantina provoca uma diminuição nos níveis de $\alpha$-caroteno e $\beta$-caroteno. Estudos epidemiológicos e clínicos mostraram que baixa ingestão ou baixa concentração desses carotenóides no plasma está associada com a degeneração macular. Os benefícios desses dois carotenóides em humanos não param na saúde dos olhos. Estudos recentes sugerem que eles podem manter a saúde do coração por reduzirem os riscos de doenças cardiovasculares e protegem a pele dos danos causados por radiação UV (SANTOCONO et al., 2007; MARINOVA; RIBAVORA, 2007).

Licopeno (Figura 3) é um isômero acíclico do $\beta$-caroteno, com atividade de pró-vitamina A, que está presente em muitas frutas e vegetais. Devido ao grande número de ligações dienos conjugadas, o licopeno é um dos mais potentes absorvedores de oxigênio singlet entre os carotenóides naturais e funciona como um antioxidante muito potente. Além 
disso, ele é capaz de reduzir a mutagênese e, em concentrações fisiológicas, pode inibir o crescimento de células humanas cancerígenas, especialmente em câncer de próstata, sem evidência de efeitos tóxicos ou apoptose celular. Umas das fontes vegetais mais ricas em licopeno é o tomate (SCOLASTICI et al., 2007; BLUM et al., 2005).<smiles>CC1=C(/C=C/C(C)=C/C=C/C(C)=C/C=C/C=C(C)/C=C/C=C(C)/C=C/C2=C(C)CCCC2(C)C)C(C)(C)CCC1</smiles>

BETACAROTENO<smiles>CC1=C(/C=C/C(C)=C/C=C/C(C)=C/C=C/C=C(C)/C=C/C=C(C)/C=C/C2=C(C)CC(O)CC2(C)C)C(C)(C)CC(C)C1</smiles>

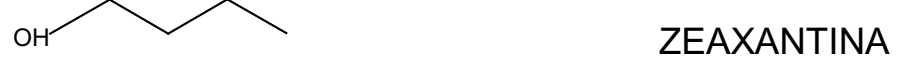<smiles>CC1=CC(O)CC(C)(C)C1/C=C/C(C)=C/C=C/C(C)=C/C=C/C=C(C)/C=C/C=C(C)/C=C/C1=C(C)CC(C)CC1(C)C</smiles>

\section{LUTEÍNA}<smiles>CC(C)=CCCC(C)=CC=CC(C)=CC=CC(C)=CC=CC=C(C)C=CC=C(C)C=CC=C(C)CCC=C(C)C</smiles>

Figura 3. Estruturas moleculares de alguns carotenóides encontrados nos vegetais. 


\section{Metodologias para determinação de carotenóides}

Métodos de extração

O método mais comumente utilizado é a extração com solventes. Devido à estrutura complexa e a diversidade desses compostos encontrados em amostras vegetais, não há um protocolo único para extraí-los (QUIRÓS; COSTA, 2006). Uma vez que os carotenóides são pigmentos lipossolúveis não saponificáveis, é comum realizar uma etapa de saponificação para remover os lipídeos que possam interferir nos procedimentos de extração com solventes apolares. A saponificação é feita utilizando-se uma solução de base, como hidróxido de potássio, em solvente polar, como metanol ou etanol, de onde os carotenóides são posteriormente extraídos (MARINOVA; RIBAVORA, 2007).

Diversos solventes ou misturas de solventes têm sido empregados nos trabalhos realizados. A (Tabela 3) apresenta alguns dos principais solventes de extração utilizados em estudos recentes.

Tabela 3. Solventes empregados na extração de carotenóides em diferentes amostras.

\begin{tabular}{ccl}
\hline Amostra & Solvente de extração & Referência \\
\hline $\begin{array}{c}\text { Cenouras, grãos verdes e } \\
\text { brócolis }\end{array}$ & Tetrahidrofurano & McINERNEY et al., 2007 \\
Suco de tomate & Tetrahidrofurano & $\begin{array}{l}\text { SÁNCHEZ-MORENO et al., } \\
2006\end{array}$ \\
Frutas vermelhas bulgarianas & Metanol:tetrahidrofurano $(1: 1, \mathrm{v} / \mathrm{v})$ & MARINOVA; RIBAVORA, 2007 \\
Calêndulas & Hexano & WANG et al., 2006 \\
Plantas comestíveis da & Hexano & CHANWITHEESUK et al., 2005 \\
Tailândia & Hexano:acetona:etanol $(2: 1: 1, \mathrm{v} / \mathrm{v} / \mathrm{v})$ & HU et al., 2008 \\
Dunaliella salina & Éter etílico, acetato de etila e éter etílico/ & SQUINA; MERCADANTE, 2003 \\
Rhodotorula & acetato de etila (1:1) &
\end{tabular}

Quantificação e identificação de carotenóides

Embora alguns autores utilizem a cromatografia à pressão atmosférica para separar carotenóides, a separação desses compostos é comumente realizada por meio de cromatografia líquida de alta eficiência, podendo ocorrer tanto em fase normal quanto em fase reversa, utilizando eluição isocrática ou em gradiente. O detector pode ser o UV/Vis ou o detector de arranjo de diodos (DAD) (CHANWITHEESUK; TEERAWUTGULRAG; RAKARIYATAM, 2005; KIOKIAS; OREOPOULOU, 2006). Quando o DAD não é suficiente, em virtude de interferências espectrais, a espectroscopia de massa (MS) acoplada à cromatografia pode ser utilizada com sucesso (SIKORA et al, 2008). A identificação de carotenóides é geralmente realizada por (1) comparação dos tempos de retenção e espectro de absorção dos picos desconhecidos com os padrões de referência e (2) adição de carotenóides padrão à amostra, para co-cromatografia. Para a quantificação dos carotenóides são utilizadas curvas de calibração com soluções de compostos padrão na absorção específica máxima. A (Tabela 4) apresenta alguns trabalhos onde a CLAE foi utilizada para identificação de carotenóides. 
Tabela 4. Análise de carotenóides por CLAE.

\begin{tabular}{|c|c|c|c|}
\hline Amostra & Eluente & Detector & Referência \\
\hline Abricós e abóbora & $\begin{array}{c}\text { A: metanol: éter metiltercibutílico: } \\
\text { água }(81: 15: 4, \mathrm{v} / \mathrm{v} / \mathrm{v}) \\
\text { B: metanol:éter } \\
\text { metiltercibutílico:água (4:92:4, } \\
\mathrm{v} / \mathrm{v} / \mathrm{v})\end{array}$ & $\begin{array}{c}\text { DAD } \\
(200-700) \mathrm{nm} \\
\text { Espectrômetro de } \\
\text { massa (MS) }\end{array}$ & KURZ et al., 2008 \\
\hline Suco de tomate & $\begin{array}{l}\text { A: acetonitrila } \\
\text { B: metanol } \\
\text { C: diclorometano } \\
\text { D: hexano }\end{array}$ & $\begin{array}{l}\text { DAD } \\
474 \mathrm{~nm}\end{array}$ & $\begin{array}{l}\text { SÁNCHEZ-MORENO et } \\
\text { al., } 2006\end{array}$ \\
\hline $\begin{array}{l}\text { Frutas vermelhas } \\
\text { bulgarianas }\end{array}$ & $\begin{array}{c}\text { A: acetonitrila:metanol }(95: 5, \mathrm{v} / \mathrm{v}) \\
\text { B:acetonitrila:metanol:acetato de } \\
\text { etila }(60: 20: 20, \mathrm{v} / \mathrm{v} / \mathrm{v})\end{array}$ & $\begin{array}{l}\text { DAD } \\
450 \mathrm{~nm}\end{array}$ & $\begin{array}{l}\text { MARINOVA; } \\
\text { RIBAVORA, } 2007\end{array}$ \\
\hline Flores marigold & $\begin{array}{c}\text { A: acetonitrila:metanol }(9: 1, \mathrm{v} / \mathrm{v}) \\
\text { B: acetato de etila }\end{array}$ & $\begin{array}{c}\text { DAD } \\
200-600 \mathrm{~nm}\end{array}$ & WANG et al., 2006 \\
\hline $\begin{array}{l}\text { Plantas comestíveis } \\
\text { da Tailândia }\end{array}$ & $\begin{array}{c}\text { Carotenos: } \\
\text { Hexano:acetone }(9: 1 \mathrm{v} / \mathrm{v}) \\
\text { Xantofilas: hexano:acetona:metanol } \\
(8: 1: 1 \mathrm{v} / \mathrm{v} / \mathrm{v})\end{array}$ & $\begin{array}{l}\text { DAD } \\
\text { Carotenos: } \\
436 \mathrm{~nm} \\
\text { Xantofilas: } \\
474 \mathrm{~nm}\end{array}$ & $\begin{array}{l}\text { CHANWITHEESUK et } \\
\text { al., } 2005\end{array}$ \\
\hline Dunaliella salina & $\begin{array}{c}\text { Metanol:acetonitrila:água }(84: 14: 2 \text {, } \\
\text { v/v/v)/ cloreto de metila }(75: 25 \\
\mathrm{v} / \mathrm{v})\end{array}$ & $\begin{array}{l}\text { DAD } \\
450 \mathrm{~nm}\end{array}$ & HU et al., 2008 \\
\hline
\end{tabular}

\section{Conclusão}

Arelação entre a concentração de compostos com atividade antioxidante em alimentos e a capacidade antioxidante de cada dado alimento ainda não está completamente esclarecida. No entanto, é fato que a ingestão continuada de alimentos ricos em carotenóides e compostos fenólicos em geral está associada à prevenção de diversos tipos de doenças degenerativas. $\mathrm{O}$ estudo da presença e concentração desses compostos nos alimentos de origem vegetal deverá se ampliar, de modo a permitir uma melhor avaliação de seus efeitos, possibilitando uma compreensão mais ampla para uma recomendação de dieta melhor embasada. A compilação apresentada no presente trabalho teve por finalidade facilitar o levantamento bibliográfico a respeito desse estudo: as principais metodologias foram indicadas, acompanhadas de extensa bibliografia recente.

\section{Referências}

AO, C.; LI, A.; ELZAAWELY, A. A.; XUAN, T. D.; TAWATA, S. Evaluation of antioxidant and antibacterial activities of Ficus microcarpa L. fil. Extract. Food Control, v. 19, p. 940-948, 2008.

BELITZ, H. D.; GROSCH, W. Food chemistry. New York: Springer Verlag, 2004. 774 p.

BELLIZI, M. C.; FRANKLIN, M. F., DUTHIE, G. G.; JAMES, W. P. T. Vitamin E and coronary heart disease: the European paradox. Eur. J. Clin. Nutr, v. 48, n. 11, p. 822-831, 1994.

BLUM, A.; MONIR, M.; WIRSANSKY, I.; BEN-AZIR, S. The beneficial effects of tomatoes. European Journal of Internal Medicine, v. 1, n. 6, p. 402- 404, 2005.

BRAND-WILLIAMS, W.; CUVELIER, M. E.; BERSET, C. Use of a free radical method to evaluate antioxidant activity. Lebensmittel-Wissenschaft Technologie, London, v. 28, p. 25-30, 1995. 
BROINIZI, P. R. B.; ANDRADE-WARTHA, E. R. S.; SILVA, A. M. O.; NOVOA, A. J. V.; TORRES, R. P.; AZEREDO, H. M. C. Avaliação da atividade antioxidante dos compostos fenólicos naturalmente presentes em subprodutos do pseudofruto de caju (Anacardium occidentale L.). Ciênc. Tecnol. Aliment, Campinas, v. 27 , n. 4, p. 902-908, 2007.

CAPECKA, E.; MARECZEK, A.; LEJA, M. Antioxidant activity of fresh and dry herbs of some Lamiaceae species. Food Chemistry, London, v. 93, p. 223-226, 2005.

CHANWITHEESUK, A.; TEERAWUTGULRAG, A.; RAKARIYATAM, N. Screening of antioxidant activity and antioxidant compounds of some edible plants of Thailand. Food Chemistry, London, v. 92, p. 491-497, 2005 .

DAMODARAN, S.; PARKIN, K.; FENNEMA, O. R. Fennema"s food chemistry. 4. ed. Boca Raton: CRC Press, 2008. 1144 p.

EFRAIM, P.; TUCCI, M. L.; PEZOA-GARCÍA, N. H.; HADDAD, R.; EBERLIN, M. N. Teores de compostos fenólicos de sementes de cacaueiro de diferentes genótipos. J. Food Technol., v. 9, n. 4, p. 229-236, 2006.

FURLONG, E. B.; COLLA, E.; BORTOLATO, D. S.; BAISCH, A. L. M. Avaliação do potencial de compostos fenólicos em tecidos vegetais. Vetor, Rio Grande, v. 13, p. 105-114, 2003.

GRAHAM, H. D. Stabilization of the Prussian blue color in the determination of polyphenols. J. Agric. Food Chem., Columbus, v. 40, n. 5, p. 801-805, 1992.

HARBORNE, J. B.; WILliAMS, C. A. Advances in flavonoid research since 1992. Phytochemistry, New York, v. 52, n. 6, p. 481- 504, 2000.

HERNÁNDEZ, A. M.; PRIETO GONZÁlES, E. A. Plantas que contienen polifenoles. Revista Cubana de Investigaciones Biomedica, Ciudad de La Habana, v.18, n. 1, p. 12-14, 1999.

HRAZDINA, G.; BORZEL, A. J.; ROBINSON, W. B. Studies on the stability of the anthocyanidin-3,5diglucosides. Am. J. Enol. Vitic., v. 21, n. 4, p. 201-204, 1970 .

HU, C.; LIN, J.; LU, F.; CHOU, F.; YANG, D. Determination of carotenoids in Dunaliella salina cultivated in Taiwan and antioxidant capacity of the algal carotenoid extract . Food Chemistry, London, v. 109, p. 439-446, 2008.

KAWANISHI, S.; MURATA, M.; TAKAHASHI, A.; SAITO, I. The role of metals in site-specific DNA damage with reference to carcinogenesis. Free Radic Biol Med, San Diego, USA, v. 32, p. 822-32, 2002.
KIOKIAS, S.; OREOPOULOU, V.Antioxidant properties of natural carotenoid extracts against the AAPH-initiated oxidation of food emulsions. Innovative Food Science and Emerging Technologies, v. 7, p. 132-39, 2006.

KURZ, C.; CARLE, R.; SCHIEBER, A. HPLC-DADMSn characterisation of carotenoids from apricots and pumpkins for the evaluation of fruit product authenticity. Food Chemistry, London, v. 110, p. 522-530, 2008.

LAGUERRE, M.; LECOMTE, J., VILLENEUVE, P. Evaluation of the ability of antioxidants to counteract lipid oxidation: Existing methods, new trends and challenges. Review. Progress in Lipid Research, v. 46, p. 244-282, 2007.

MAISUTHISAKUL, P.; $\quad$ SUTTAJIT, M.; PONGSAWATMANIT, R. Assessment of phenolic content and free radical-scavenging capacity of some Thai indigenous plants. Food Chemistry, London, v. 100, p. 1409-1418, 2007.

MARINOVA, D.; RIBAROVA, F. HPLC determination of carotenoids in Bulgarian berries. Journal of Food Composition and Analysis, Davis, v. 20, n. 5, p. 370-374, 2007.

McINERNEY, J. K.; SECCAFIEN, C. A.; STEWART, C. M.; BIRD, A. R. Effects of high pressure processing on antioxidant activity, and total carotenoid content and availability, in vegetables. Innovative Food Science and Emerging Technologies, v. 8, n. 4, p. 543-548, 2007.

McLEAN, J.A.; KARADAS, F.; SURAI, P.; McDEVITTI, R.; SPEAKE, B. Lipid-soluble and water-soluble antioxidant activities of the avian intestinal mucosa at different sites along the intestinal tract. Comparative Biochemistry and Physiology, v. 141, n. B, p. 366- 372, 2005.

McNULTY, H. P.; BYUN, J.; LOCKWOOD, S. F.; JACOB, R. F.; MASON, P. Differential effects of carotenoids on lipid peroxidation due to membrane interactions: X-ray diffraction analysis. Biochimica et Biophysica Acta, v. 1768, n. 1, p. 167-174, 2007.

MURCIA, M. A.; EGEA, I.; ROMOJARO, F.; PARRAS, P.; JIMÉNEZ,A.M.; MARTÍNEZ-TOMÉ, M.Antioxidant evaluation in dessert spices compared with common food additives, influence of irradiation procedure. Journal of Agricultural and Food Chemistry, Easton, v. 52, p. 18721881, 2004.

NASS, L. L. Recursos genéticos vegetais. Brasília: Embrapa Recursos Genéticos Vegetais e Biotecnologia, 2007.

PAREJO, I.; VILADOMAT, F.; BASTIDA, J.; ROSASROMERO,A.; FLERLAGE, N.; BURILLO, J.; CODINA, 
C. Comparison between the radical-scavenging activity and antioxidant activity of six distilled and non-distilled mediterranean herbs and aromatic plants. Journal of Agricultural and Food Chemistry, Easton, v. 50, n. 23, p. 6882-6890, 2002.

PODSEDEK, A. Natural antioxidants and antioxidant capacity of Brassica vegetables: A review. LWT-Food Sci. Technol, v. 40, p. 1-11, 2007.

QUIRÓS, A. R.; COSTA, H. S. Analysis of carotenoids in vegetable and plasma samples: A review. Journal of Food Composition and Analysis, v. 19, p. 97-111, 2006.

RICE-EVANS, C. A.; MILLER, N. J.; PAGANGA, G. Structure-antioxidant activity relationships of flavonoids and phenolic acids. Free Radical Biology and Medicine, New York, v. 20, n. 7, p. 933-956, 1996.

ROSSI JUNIOR, J. A.; SINGLETON, V. L. Colorimetry of total phenolics with phosphomolybdic phosphotungstic acid reagents. American Journal of Enology and Viticulture, v. 16, n. 3, p. 144-158, 1965.

SÁNCHEZ-MORENO, C. Methods used to evaluate the free radical scavenging activity in foods and biological systems. Food Science Technology International, v. 8, n. 3, p. 121-137, 2002.

SÁNCHEZ-MORENO, C.; PLAZA, L.; ANCOS, B.; CANO, M. P. Nutritional characterisation of commercial traditional pasteurised tomato juices: carotenoids, vitamin $\mathrm{C}$ and radical-scavenging capacity. Food Chemistry, London, v. 98, p. 749-756, 2006.

SANTOCONO, M.; ZURRIA, M.; BERRETTINI, M.; FEDELI, D.; FALCIONI, G. Lutein, zeaxanthin and astaxanthin protect against DNA damage in SK-N-SH human neuroblastoma cells induced by reactive nitrogen species. Journal of Photochemistry and Photobiology B: Biology, v. 88, n. 1, p. 1-10, 2007.

SCOLASTICI, C.; LIMA, R. O.; BARBISAN, L. F.; FERREIRA, A. L.; RIBEIRO, D. A.; SALVADORI, D. M. Lycopene activity against chemically induced DNA damage in Chinese hamster ovary cells. Toxicology in Vitro, v. 21, p. 840-845, 2007.
SIKORA, E.; CIESLIK, E.; LESZCZYNSKA, T.; FILIPIAK-FLORKIWUACZ, A.; PISULEWSKI, P. M. The antioxidant activity of selected cruciferous vegetables subjected to aquathermal processing. Food Chemistry, London, v. 107, p. 50-55, 2008.

SQUINA, F. M.; MERCADANTE, A. Z. Análise, por CLAE, de carotenóides de cinco linhagens de Rhodotorula. Revista Brasileira de Ciências Farmacêuticas, São Paulo, v. 39, n. 3, p. 309-318, 2003.

STREET, D. A.; COMSTOCK, G. W.; SALKELD, R. M.; SCHUEP, W.; KLAG, M. J. Serum antioxidants and myocardial infarction. Circulation, Dalas, v. 90, p. 11541161, 1994.

TAYZ, L.; ZEIGER, E. Fisiologia vegetal. 3. ed. Porto Alegre: Artmed, 2004.

VAN ACQUIRE, S. A. Structural aspects of antioxidant activity of flavonoids. Free Radic Biol Med., v. 20, n. 3, p. 331-342, 1996.

VASCO, C.; RUALES, J.; KAMAL-ELDIN, A. Total phenolic compounds and antioxidant capacities of major fruits from Ecuador. Food Chemistry, London, v. 111, p. 816-823, 2008.

VÁZQUEZ, G.; FONTENLA, E.; SANTOS, J.; FREIRE, M. S.; GONZÁLEZ- ÁLVAREZ, J.; ANTORRENA, G. Antioxidant activity and phenolic content of chestnut (Castanea sativa) shell and eucalyptus (Eucalyptus globulus) bark extracts. Industrial crops and products, v. 28, p. 279-285, 2008.

WANG, M.; TSAO, R.; ZHANG, S.; DONG, Z.; YANG, R.; GONG, J.; PEI, Y. Antioxidant activity, mutagenicity/ anti-mutagenicity, and clastogenicity/anti-clastogenicity of lutein from marigold flowers. Food and Chemical Toxicology, v. 44, p. 1522-1529, 2006.

YILMAZ, Y.; TOLEDO, R. T. Oxygen radical absorbance capacities of grape/wine industry byproducts and effect of solvent type on extraction of grape seed polyphenols. Journal of Food Composition and Analysis, v. 9, n. 1, p. 41-48, 2006. 
